\title{
ESTRATÉGIAS DE ENSINO-APRENDIZAGEM COM ALUNOS PORTADORES DE DEFICIÊNCIA INTELECTUAL NA DISCIPLINA DE PORTUGUÊS
}

\author{
Kátia Eliane Santos Avelar, Centro Universitário Augusto Motta (UNISUAM) \\ Maria Geralda Miranda, Centro Universitário Augusto Motta (UNISUAM) \\ Shirley Araujo Cabral, Centro Universitário Augusto Motta (UNISUAM)
}

\begin{abstract}
RESUMO
O presente estudo teve como objetivo identificar e analisar o desenvolvimento cognitivo de alunos com deficiência intelectual e a importância do ensino de português como um dos aspectos da educação inclusiva. $\mathrm{O}$ principal enfoque foi estabelecer uma relação entre as dificuldades apresentadas por alunos com deficiência intelectual e as práticas pedagógicas utilizadas no processo de ensino/aprendizagem na disciplina de português, ministradas no Ensino Fundamental da Escola Municipal Márcio Fiat, localizada em Duque de Caxias. No decorrer da pesquisa, foi possível constatar que os alunos, submetidos a um acompanhamento pedagógico planejado a partir da realidade específica de cada um, conseguiram se interessar mais pelos conteúdos ministrados em sala de aula. As medidas adotadas trouxeram vários benefícios, dentre os quais podemos destacar a melhora da auto-estima e o aumento da capacidade de se relacionar com colegas e professores. Foi possível perceber ainda, que os alunos mostraram-se progressivamente independentes e estimulados.
\end{abstract}

PALAVRAS-CHAVE: Deficiência intelectual - Língua Portuguesa - Estratégias de Ensino Educação Especial Inclusiva.

\begin{abstract}
The present study had as objective to analyze the challenges faced in the pedagogical practices adopted, in the school routine, before an inclusive proposal. The main focus was to establish a relationship between the difficulties presented by students with intellectual disabilities and the pedagogical practices used in the teaching / learning process in the Portuguese language, taught at the Elementary School of the Municipal School Márcio Fiat, located in Duque de Caxias. The purpose was to describe the pedagogical practices adopted, in order to understand the challenges faced, in the daily school, before an inclusive proposal. In the course of the research, it was possible to verify that the students, submitted to a pedagogical follow-up planned from the specific reality of each one, were able to become more interested in the content taught in the classroom. The measures adopted brought several benefits, among which we can highlight the improvement of self-esteem and the increase of the capacity to relate with colleagues and teachers. It was also possible to see that the students were progressively independent and stimulated.
\end{abstract}

KEYWORDS: Intellectual disability - Portuguese language - Strategies for Teaching - Inclusive Special Education. 


\section{INTRODUÇÃOO}

A trajetória da presente investigação é resultado de experiência compartilhada com alunos de uma escola da rede pública municipal de Ensino Fundamental Municipal Márcio Fiat, localizada no município de Duque de Caxias, Estado do Rio de Janeiro. Algumas motivações nos levaram a escolher a escola estudada, foram elas: o fato dela pertencer ao sistema público de ensino municipal de Duque de Caxias; a demonstração de interesse, dos profissionais que ali atuam, em participar da pesquisa.

A questão do seu espaço físico, pois ela possui uma sala de atendimento educacional especializado com profissionais e recursos materiais e tecnológicos apropriados; Ter em seu Projeto Político Pedagógico a intenção de ser uma escola verdadeiramente inclusiva; Exercer o cargo de vice-diretora do laboratório de informática educativa, tendo trabalhado cerca de três anos na Sala de Recursos atendendo alunos inclusos.

Este artigo está organizado em três momentos distintos, porém interligados entre si. No primeiro, apresentamos a questão da inclusão escolar do aluno com deficiência intelectual que servirá de base para o presente trabalho. No segundo momento faremos uma abordagem acerca do processo de conscientização dos indivíduos acerca da educação inclusiva e da desmistificação da deficiência intelectual.

No terceiro, serão colocadas algumas considerações sobre o ensino na perspectiva inclusiva. Em sequência apresentaremos a metodologia adotada e os resultados da pesquisa. E finalmente, é apresentada a conclusão da pesquisa.

Assim é que o presente trabalho propõe-se a oferecer um espaço de reflexão sobre a mediação pedagógica na perspectiva inclusiva para aprendizagem da língua portuguesa aos alunos com Deficiência Intelectual, descrevendo e analisando minuciosamente as peculiaridades da Deficiência Intelectual do processo de ensinoaprendizagem.

\section{INCLUSÃO ESCOLAR DO ALUNO COM DEFICIÊNCIA INTELECTUAL}

De acordo com Silva e Rosa (2010, p. 2) a Declaração de Salamanca, os alunos com deficiência, têm direito à educação regular igualmente com as demais pessoas, independente de suas necessidades especiais: 
As escolas devem acolher todas as crianças, independentemente de suas condições físicas, intelectuais, sociais, emocionais, linguísticas ou outras. Devem acolher crianças com deficiência e crianças bem dotadas; crianças que vivem nas ruas e que trabalham; crianças de populações distantes ou nômades; crianças de minorias linguísticas, étnicas ou culturais e crianças de outros grupos ou zonas desfavorecidas ou marginalizadas (DECLARAÇÃO DE SALAMANCA: CORDE, 1994, p.73 apud SILVA e ROSA, 2010).

De acordo com Goffredo (1992), frente a esse novo paradigma educativo, a escola deve ser definida como uma instituição social que tem por objetivo atender todas as crianças, sem exceção. Ela deve ser aberta, pluralista, democrática e de qualidade. Portanto, deve manter suas portas abertas, inclusive para pessoas com necessidades educacionais especiais. O modelo de escola que se deseja para a sociedade deve conter, em seu projeto educativo, a idéia de unidade na diversidade, porquanto inviável a coexistência entre democracia e exclusão.

Assim, o espaço escolar pode e deve ser o local onde os alunos criam e recriam conhecimento, possibilitando novas maneiras de interpretar o mundo que, certamente, beneficiarão o convívio harmônico na sociedade. O referencial professor de matemática do tipo "sabe tudo", muito presente na comunidade educadora, torna-se um profissional excludente por suas características baseadas no rigor, na memorização de regras e no extenso cumprimento de exercícios.

Tardif (2002) defende que o saber não se reduz, exclusiva ou principalmente, a processos mentais, cujo suporte é a atividade cognitiva dos indivíduos, mas é, também, um saber social que se manifesta nas relações complexas entre professores e alunos. E afirma ainda que é imprescindível a necessidade de "situar o saber do professor na interface entre o individual e o social, entre o ator e o sistema, a fim de captar a sua natureza social e individual como um todo" (TARDIF, 2002, p.16).

Acerca do tema Deficiência Intelectual cabe destacar que "É preciso ter uma visão positiva da deficiência, pois uma criança com deficiência não é uma criança defeituosa" (VIGOTSKY, 1995).

De acordo com o Ministério da Educação e Cultura, os resultados do Censo Escolar da Educação Básica de 2008 apontam um crescimento significativo nas matrículas da educação especial nas classes comuns do ensino regular. O índice de 
matriculados passou de 46,8\% do total de alunos com deficiência em 2007, para 54\% no ano de 2008. Logo, estão matriculados em classes comuns, cerca de 375.772 estudantes com deficiências, transtornos globais do desenvolvimento e altas habilidades ou superdotação inclusivos (MEC, 2010).

Esse crescimento é reflexo da política implementada pelo Ministério da Educação, que inclui programas de implantação de salas com recursos multifuncionais, de adequação dos prédios escolares para a acessibilidade; de formação continuada aos professores da educação especial e do Benefício de Prestação Continuada da Assistência Social na escola, além do programa "Educação Inclusiva: Direito à Diversidade". O propósito desses programas é estimular a formação de gestores e educadores para a criação de sistemas educacionais inclusivos (MEC, 2010).

Entretanto, a inclusão de alunos com necessidades educacionais especiais em turmas regulares de ensino têm deixado falhas no processo de aprendizagem, particularmente no que se refere ao ensino e aprendizagem de conceitos matemáticos.

Segundo Santana (2010, p.31), a modalidade de Ensino Especial, vêm ocupando um único espaço, geralmente constituído como um espaço de exclusão. O processo de inclusão não se refere somente a alunos com necessidades educacionais especiais, mas abrange, também, todas as pessoas sem discriminação de raça, credo, cor e etc.

Nesse sentido, Mantoan (2005, p.1) afirma que a

Inclusão é a nossa capacidade de entender e reconhecer o outro e, assim, ter o privilégio de conviver e compartilhar com pessoas diferentes de nós. A educação inclusiva acolhe todas as pessoas, sem exceção. É para o estudante com deficiência física, para os que têm comprometimento mental, para os superdotados, para todas as minorias e para a criança que é discriminada por qualquer outro motivo.

Os Parâmetros Curriculares Nacionais da Educação Especial trazem a inclusão como um processo:

Gradual, interativo e culturalmente determinado, requerendo a participação do próprio aluno na construção do ambiente escolar que lhe seja favorável [...], alguns educadores defendem que uma escola não precisa preparar-se para garantir a inclusão de alunos com necessidades especiais, mas tornar-se preparada como resultado do ingresso desses alunos (BRASIL, 1998, p.18). 
Tais Parâmetros Curriculares sugerem, ainda, a colocação imediata de todos os educandos com necessidades especiais na escola, conforme segue:

A escola para todos requer uma dinamicidade curricular que permita ajustar o fazer pedagógico às necessidades dos alunos. Ver as necessidades especiais dos alunos atendidas no âmbito da escola regular requer que os sistemas educacionais modifiquem, não apenas as suas atitudes e expectativas em relação a esses alunos, mas, também, que se organizem para constituir uma real escola para todos, que dê conta dessas especificidades (BRASIL, 1998, p. 31).

Ademais, conforme o artigo $3^{\circ}$ da resolução $n^{\circ}$. 2, de 11 de setembro de 2001, que institui acerca das Diretrizes Nacionais para a Educação Especial na Educação Básica:

Por educação especial, modalidade da educação escolar, entende-se um processo educacional definido por uma proposta pedagógica que assegure recursos e serviços educacionais especiais, organizados institucionalmente para apoiar, complementar, suplementar e, em alguns casos, substituir os serviços educacionais comuns, de modo a garantir a educação escolar e promover o desenvolvimento das potencialidades dos educandos que apresentam necessidades educacionais especiais, em todas as etapas e modalidades da educação básica (BRASIL, 2001, p.1).

Para Mitler (2003), está claro que as leis e normas que regem a educação e a sociedade em nosso país amparam e defendem o processo de inclusão, tanto social quanto educacional, de pessoas com diferentes necessidades especiais. Porém, esse amparo ainda não vem ocorrendo na prática, onde há um evidente distanciamento entre as políticas propostas e cumprimento destas.

Ainda segundo Mittler (2003, p.24) "o que acontece nas escolas é um reflexo da sociedade em que elas funcionam". O problema ocorre quando a comunidade onde a escola está inserida apresenta uma realidade excludente, afastando a compreensão de sujeito histórico-cultural, e atribuindo às pessoas deficientes, estigmas e rótulos estabelecidos pela própria comunidade.

Colaborando com a problemática em foco está o fato dos sistemas escolares estarem organizados de maneira que se permita a divisão nos atendimentos de alunos 
tidos como "normais" e de alunos tidos como "deficientes", dentro das modalidades de ensino regular e especial, de professores e especialistas em diversas áreas, principalmente, nas áreas onde o foco são manifestações das diferenças (MANTOAN, 2005).

\section{ALUNOS COM NECESSIDADES ESPECIAIS}

O termo deficiência é usado para definir a ausência ou disfunção de uma estrutura psíquica, fisiológica ou anatômica do ser humano. As crianças que possuem um desenvolvimento diferenciado por apresentarem lesões em seu aparato sensorial, físico e/ou cognitivo, são consideradas deficientes (SILVA; RIBEIRO: MIETO, 2010)

Nesse sentido, os autores assim se manifestam:

Esses sujeitos considerados deficientes recebem esse crivo social, no momento em que se realiza o diagnóstico. A partir daí, todas as suas interações com o mundo são constituídas com base no dado da deficiência como lugar de anormalidade (SILVA; RIBEIRO: MIETO, 2010, p.21)

Outrossim, na dinâmica interativa dessa realidade escolar discriminatória, o sujeito vai tomando para si (internaliza) o sentido de que é incapaz, e com isso automaticamente começa a paralisar subjetivamente suas possibilidades de desenvolvimento, socialização e de produtividade, ou seja, após ser diagnosticado e estigmatizado como deficiente ou anormal, o sujeito passa a se convencer de que é realmente incapaz, de tal modo que não mais se esforça para superar os obstáculos comuns a vida de qualquer pessoa.

Silva, Ribeiro e Mieto (2010) entendem que é necessário resistir ao conceito de deficiência, enquanto expressão de uma negatividade. Nesse sentido é que o termo "pessoas com necessidades especiais" foi amplamente adotado pelos doutrinadores pedagógicos, de tal modo que o problema da deficiência está mais relacionado a uma diferença na forma de entender e compreender o mundo (desenvolvimento atípico), do que a uma impossibilidade do indivíduo.

Sassaki (2003) afirma, no entanto, que as pessoas com deficiência, nos movimentos pelos seus direitos ao redor do mundo, incluindo o Brasil, nos debates travados sobre a nomenclatura pela qual desejam ser designadas, optaram pelo termo: 
"pessoas com deficiência", justificando entre outras coisas, que esse nome valoriza as diferenças e necessidades decorrentes das deficiências.

Por outro lado, no que tange ao termo deficiência intelectual, este se refere ao funcionamento do intelecto e não ao funcionamento da mente como um todo, afirma Sassaki (2005), e continua que, em 2004, a Organização Mundial da Saúde e a Organização Pan-Americana da Saúde realizaram um evento no Canadá, onde o Brasil também tomou parte, ocasião em que foi aprovada a Declaração de Montreal Sobre Deficiência Intelectual e esse termo passou a ser utilizado também em outros idiomas como o espanhol, francês e inglês.

Há bem pouco tempo as pessoas acreditavam que as crianças com deficiência intelectual seriam fisicamente impossibilitadas de possuir um pensamento desvinculado de suas traumáticas experiências concretas, bem como seriam impossibilitadas de alcançar níveis mais elevados no pensamento abstrato (SASSAKI, 2005).

Contudo, pesquisas posteriores a esse ultrapassado conceito revelam que essa forma de se posicionar está absolutamente equivocada, pois referido diagnóstico possui limitações e os sujeitos em questão, muitas vezes, rompem com as expectativas esperadas, apresentando um desenvolvimento mental muito mais avançado que aqueles indicados em avaliações quantitativas (SASSAKI, 2005).

Não obstante isso, Vigotsky (1995 p. 104) afirma que:

Para a educação da criança com deficiência intelectual é importante conhecer o modo como ela se desenvolve. Não importa a deficiência e a insuficiência em si mesmas (ou o defeito), mas a reação de sua personalidade em desenvolvimento no enfrentamento das dificuldades decorrentes da deficiência.

Assim sendo não se pode mensurar o nível mental que uma criança será capaz de atingir, apesar de apresentar peculiaridades em seu desenvolvimento, pois o processo de constituição da pessoa é ilimitado, conforme preconiza Carlo (1999, p.32).

Nesta perspectiva, não há uma evolução linear de funções parciais, crescentes ou deficitárias do ponto de vista quantitativo, mas revoluções qualitativas relacionadas com a aparição de formas novas ou mais avançadas de mediação instrumental e/ou semiótica. 
Mitler (2003) afirma que é que precisamos reestruturar as escolas de modo que assumam a inclusão de fato, onde as atitudes e práticas excludentes sejam extintas. "Criar um processo de reforma e de reestruturação das escolas como um todo, com o objetivo de assegurar que todos os alunos possam ter acesso a todas as gamas de oportunidades educacionais e sociais oferecidas pela escola" (MITLER 2003, p.25).

E para que isso realmente ocorra, é necessário um processo de conscientização dos indivíduos e de desmistificação das deficiências. Não se deve amparar a escola excludente, considerada aquela onde o aluno é simplesmente lotado em uma classe de ensino regular e o professor não tem formação básica para desenvolver um trabalho significativo junto aos alunos (MITLER 2003).

\section{O PROFESSOR NA PERSPECTIVA INCLUSIVA}

De acordo com Vigotsky (2003), o professor é organizador do ambiente social. Assim, deve estar pronto para realizar várias funções, permitindo que o aluno se revele conforme o nível de desenvolvimento alcançado.

Assim as práticas pedagógicas e didáticas apontam no sentido de que assumir-se como professor requer a clareza e o conhecimento de todos os aspectos constituintes da missão a ser realizada, pois o professor somente promoverá a aprendizagem de seu aluno na medida em que interferir em sua atividade psíquica, ou seja, quando o aluno passar a dirigir o seu próprio processo de aprendizagem (TUNES, TACCA e BARTHOLO, 2005).

Entretanto, Vigotsky (2003) ao destacar a função do professor e a do aluno faz afirmações contraditórias quando diz:

A rigor, do ponto de vista científico, não se pode educar a outrem diretamente. Não é possível exercer uma influência direta e produzir mudanças em um organismo alheio, só é possível educar a si mesmo, isto é modificar as reações inatas através da própria experiência (VIGOTSKY, 2003, p.75).

A posição contraditória de Vigotsky (2003) não pode ser interpretada como se ele só defendesse ora a educação pelo autoritarismo, ora a educação das tendências à liberdade, 
devendo ser interpretada como uma ação educativa pautada por uma orientação antropológica específica.

A idéia de que o professor tem o papel de mediador, atribuída por alguns doutrinadores, é contestada ao pensarmos na atividade do professor sob uma perspectiva histórico-cultural. Pois, se o professor assim o fosse (somente mediador) seria incompleta a sua função. Ora, o ser humano é uma pessoa vulnerável à alteridade do aluno, sendo com isso, o homem social que interage e interdepende de outros indivíduos.

O professor tem de ter a sensibilidade para conhecer e compreender o aluno, além da responsabilidade e compromisso em assumir sua missão de organizador do ambiente social, permitindo que o aluno dirija o seu próprio processo de aprendizagem. Assim sendo, o professor precisa ter didática, conteúdo e conhecer o seu aluno, a ponto de, acreditando nele, valorizá-lo e incentivá-lo (VIGOTSKY, 2003).

O educador necessita, no mínimo: transmitir conhecimentos com autonomia e dedicação e que haja discípulos que queiram ser moldados. Assim é que se evidencia a forte ligação entre a psicologia e a educação. Apesar disso, nossas escolas ainda não se conscientizaram do relevante papel da diversidade nas formas de aprender (GONZALEZ-REY, 1995).

A proposta, apresentada pelo Ministério da Educação e Cultura, acerca da política nacional de educação especial na perspectiva da educação inclusiva destaca que, para atuar na educação especial, o professor deve ter como base da sua formação, inicial e continuada, conhecimentos gerais para o exercício da docência e conhecimentos específicos da área. Essa formação possibilita a atuação do docente no atendimento educacional especializado. Entretanto, esta é uma realidade ainda muito distante das escolas públicas brasileiras, haja visto que ainda há muito a ser feito para a concretização deste projeto.

Neste contexto, a missão do professor consiste em estabelecer metas e objetivos e saber sobre o que vai ensinar sem perder de vista o aluno que é para quem se está ensinando. Essa integração professor-aluno requer do profissional desempenhar diversas faces, utilizar-se de diversas estratégias para atingir seus objetivos. Esse é o profissional comprometido, responsável e, muitas vezes, angustiado por se deparar com políticas que lhe são impostas sem a menor formação e informação de como vão se desenvolver

O Ministério da Educação e Cultura, através do documento intitulado "Orientações Gerais" e formulado para a Rede Nacional de Formação Continuada de 
Professores, deixa bem claro, quando destaca que o professor deve ter como base da sua formação, inicial e continuada, conhecimentos gerais e específicos para o exercício da docência. Desse modo, entendemos plausível que o Ministério da Educação, através de suas Secretarias se responsabilizassem pela capacitação de seus professores para atuarem no projeto de inclusão. Contudo, o que se percebe atualmente é o oposto, pois os professores se vêem sozinhos e desamparados, tendo de ser criativos e dinâmicos ao desenvolverem estratégias para que o processo ensino-aprendizagem não seja comprometido.

Um verdadeiro ato educacional, para que alcance o seu objetivo de formar um cidadão autônomo, competente e crítico, não pode se limitar a uma simples relação de ensino-aprendizagem. É necessário ter vontade de incidir ou intervir no processo de aprendizagem do aluno, refletindo numa série de decisões de ordem pedagógica, que envolva todo o processo educativo desde a elaboração do currículo, até as práticas escolares da sala de aula. Assim, a atividade de ensino-aprendizagem deve ser conjunta, articulada e determinada pela interação entre os envolvidos (MARTINEZ, 2006).

Como destaca Vigotsky (2001, p. 449)

Deixe inteiramente a condição de estojo e desenvolva todos os aspectos que respiram dinamismo e vida. Em todo trabalho docente do velho tipo formavam-se forçosamente um certo bolor e ranço, como em água parada e estagnada. E aqui de nada servia a costumeira doutrina segundo a qual o mestre tem uma missão sagrada e consciência de seus objetivos ideais.

A criatividade no trabalho pedagógico deve ser vista como forma de realizar algo inédito, capaz de resultar em aspectos positivos para a aprendizagem, para o desenvolvimento dos alunos e do professor. Trata-se de atividade que é analisada a partir do novo que o professor faz, sem a desnecessária preocupação pontual com relação ao seu impacto real na aprendizagem (MARTINEZ, 2006).

Assim é que a educação inclusiva implica em uma alta dose de criatividade e de inovação na instituição escolar, a fim de derrubar os paradigmas construídos num longo processo histórico de padronização e homogeneização dos processos educativos.

Quanto ao processo de aprendizagem, Vigotsky (1989, p.105) afirma que 
A importância de se reconhecer como esta se desenvolve, e não a deficiência/insuficiência em si mesma e, sim, a reação que se apresenta na personalidade desta no processo de desenvolvimento em resposta a sua dificuldade e da qual resulta sua deficiência. Esta criança não se forma somente pelos seus defeitos, seu organismo se reorganiza como um todo. A personalidade como um todo, se equilibra, se compensa com os processos de desenvolvimento.

Assim é que, todas as intervenções cognitivas, sugeridas pelos autores acima mencionados, representam diferentes meios, cujo objetivo comum é levar as crianças com deficiência intelectual a se desenvolverem, utilizando de forma espontânea suas próprias estratégias cognitivas cheguem a um nível de consciência cada vez mais avançado de suas habilidades mentais.

\section{PROCEDIMENTOS METODOLÓGICOS}

A pesquisa constituiu um estudo de caso descritivo, com abordagem qualitativa dos dados. Como técnica de coleta e registro dos dados, utilizou-se a observação participante. Foram utilizados, para efeito de registro, os seguintes materiais: diário de campo, formulários de entrevistas semi-estruturadas com os profissionais pedagógicos da instituição com o fito de elencar as teorias didático-pedagógicas utilizadas em cada atividade e procedimento escolar, atividades impressas, observações nos diferentes ambientes da escola.

Nos trabalhos de campo que serviram de embasamento para o presente estudo, foram estruturadas diversas atividades voltadas para a área do conhecimento de português, atividades estas que podiam ser escritas como também realizadas a partir do uso de materiais didáticos/pedagógicos. Todas as observações e conclusões relevantes foram registradas em um diário de campo, de acordo com cada atividade.

O estudo contou também com uma minuciosa análise dos materiais pedagógicos disponibilizados aos alunos, tais como exercícios, avaliações, agendas escolares (como meio de comunicação entre pais e escola) e pauta onde são registradas freqüências e conteúdo ministrado em cada aula. O período de aplicação do presente estudo foi realizado durante o ano letivo de 2016.

A escola Municipal Marcio Fiat está localizada no bairro de Parada Angélica em Duque de Caxias/RJ e possui vários alunos dotados de necessidades educativas especiais que demandam um trabalho diferenciado e adaptado às suas habilidades e 
necessidades. A escola possui Educação Infantil, Educação de Jovens e Adultos Supletivo, Ensino Fundamental e Educação Especial. Há 10 salas de aulas, Sala de professores, Sala de recursos multifuncionais para Atendimento Educacional Especializado (AEE), Biblioteca, Sala de leitura, Dependências e vias adequadas a alunos com deficiência ou mobilidade reduzida, Despensa, Almoxarifado e Pátio coberto.

Há sala da direção com um computador, dois telefones, impressora, televisão, um banheiro e uma dispensa onde são guardados os materiais escolares e de escritório, sala dos professores, com dois banheiros, dois computadores para uso dos professores, uma geladeira, um bebedouro e um forno de micro ondas. $\mathrm{Na}$ secretaria há três computadores, um telefone e uma impressora, oficial e uma máquina fotocopiadora, sala de informática, sala de leitura, cozinha e refeitório, alimentação escolar para os alunos e uma cozinha para os funcionários, pátio para recreação, pátio infantil e quatro banheiros para os alunos, sendo um para os alunos com deficiência ou mobilidade reduzida

A Escola selecionada para participar da pesquisa foi escolhida também por ser onde a pesquisadora atualmente exerce o cargo de vice-diretora, tendo trabalhado cerca de três anos na Sala de Recursos atendendo alunos inclusos, acompanhando e acreditando no crescimento e desenvolvimento do processo de aprendizagem dos alunos.

Outro fator importante que também corroborou para esta pesquisa foi fato dos profissionais envolvidos nesta pesquisa enfrentarem diversos desafios durante $o$ planejamento de suas práticas docentes. Essa angústia dos mesmos fez com que se vissem motivados para o estudo em análise, pois eles sentiam necessidade de desenvolver intervenções pedagógicas criativas, hábeis a verdadeiramente auxiliar os alunos que não conseguem entender ou compreender o que se passa na sala de aula.

Desse modo, buscamos compreender a interação do professor de português com os referidos alunos e em anotações colhidas a partir das observações realizadas no dia-adia escolar dos alunos selecionados, dos professores e demais colaboradores pedagógicos que se disponibilizaram a contribuir com os trabalhos.

Participaram da pesquisa alunos do turno matutino, sendo um do $4^{\circ}$ ano e outro do $5^{\circ}$ ano, ambos do Ensino Fundamental; Ao todo participaram intensamente da pesquisa dois alunos, duas professoras de português e um professor especializado em 
educação especial. Os alunos foram escolhidos por terem como diagnóstico a Deficiência Intelectual. Eles possuem a mesma idade, qual seja: doze anos, porém pertenciam a turmas diferentes.

\section{DISCUSSÃO DOS RESULTADOS}

Após a realização deste trabalho constatamos que as práticas pedagógicas utilizadas na construção da aprendizagem na disciplina de português, para os alunos com necessidades educacionais especiais, eram eficazes, ao passo em que as aulas não se faziam cansativas para esses alunos, o que ocorria quando os professores e demais profissionais imbuídos da função pedagógica de ensinar, alternavam o conteúdo teórico com as experiências cotidianas, ilustrações e vídeos extraídos dos recursos tecnológicos ofertados, através da informática.

Isto que pôde ser observado quando as professoras estabeleceram pequenos horários diferenciados como meio de garantir, para cada aula teórica, um período fixo no laboratório de informática, oportunidade em que buscariam fixar melhor os conteúdos, através da tecnologia.

Diante do dinamismo das aulas, tanto o Aluno1, quanto o Aluno 2, se sentiam mais estimulados a participar, e com isso, interagiam de maneira mais profunda com os demais colegas e professores. Ao término deste trabalho, foi possível constatar que os alunos, submetidos a um acompanhamento de mediação pedagógica planejada e flexibilizados, a partir da realidade (social, financeira, afetiva e familiar) de cada um, conseguiam se interessar mais pelos conteúdos ministrados em sala de aula e, com isso, desenvolveram suas auto-estimas e aprimoraram seus relacionamentos com os demais colegas e professores, de tal modo que, a cada dia, se tornavam mais independentes e estimulados a manifestarem suas opiniões críticas, agindo de forma responsável e solidária.

Outro aspecto pedagógico relevante, na construção do saber, respeito à aproximação dos conteúdos ministrados com os temas que são focos de interesse dos alunos. Para isso, fez-se necessário que o professor, antes de iniciar sua atividade inerente ao processo de ensino-aprendizagem, realizasse uma investigação acerca dos interesses daquela turma, buscando saber: o que estimula a participação do grupo, o que 
faz parte do cotidiano daquelas crianças; o que desperta a atenção; qual tema traduz a história de vida destes alunos; dentre outros.

Logo, independente do rótulo que carregam de portadores de necessidades educativas especiais, esses alunos conseguiram quebrar alguns paradigmas construídos ao longo da história da humanidade, relacionados à suposta ausência de capacidade de desenvolvimento dessas pessoas. A realidade exige adequação, e não, preconceito e discriminação. Os progressos atingiram todos os envolvidos de tal modo, que se a idéia fosse adotada por todas as instituições de ensino, não seria exagero dizer que, ao menos, teríamos cidadãos muito mais solidários, ativos e participativos na sociedade.

\section{CONSIDERAÇÕES FINAIS}

Diante do que observamos no decorrer do presente trabalho, foi possível constatar que os professores de português, diante da perspectiva inclusiva, mostraram-se dispostos a planejar e rever suas estratégias de ensino, a fim de reformular e adequar-se aos interesses dos alunos, em constante transformação. Nesse contexto, os professores da referida disciplina que atuaram com os alunos, alvos da pesquisa, possuíam objetivos curriculares e serem alcançados no prazo de um ano. Contudo, as metodologias aplicadas ao longo do ano foram sofrendo transposições didáticas, a fim de atender e despertar aos interesses e ritmos de aprendizagem. Foi possível perceber que as medidas adotadas trouxeram vários benefícios, dentre os quais podemos destacar a melhora da auto-estima e o aumento da capacidade de se relacionar com colegas e professores.

Espera-se que com este trabalho possa auxiliar de certa com forma, com pequenas informações discorridas nesta pesquisa para acadêmicos, profissionais do ensino de português e, também para famílias com filhos com necessidades especiais.

Sabemos que não é um assunto acabado e que também este estudo possa estimular novas pesquisas para que haja uma valorização cada vez maior deste tema que envolve os alunos com necessidades especiais, principalmente com a deficiência intelectual, foco central deste trabalho.

\section{REFERÊNCIAS}

BRASIL. Diretrizes e Bases da Educação Nacional. São Paulo: Editora do Brasil S/A, 1998. BRASIL. Diretrizes e Bases da Educação Nacional. São Paulo: Editora do Brasil S/A, 2001. 
CARLO, M. M. R. P. Se essa casa fosse nossa. Instituições e processos de imaginação na educação especial. São Paulo: Plexus Editora, 1999.

GOFFREDO, Vera Lucia Flor S. de. Educação especial: tendências atuais. Brasília: Associação de Comunicação Educativa; Roquete Pinto, 1999.

GONZÁLES REY, F. L. O sujeito que aprende: desafios do desenvolvimento do tema da aprendizagem na psicologia e na prática pedagógica. In TACCA, Maria Carmen (Org). Aprendizagem e trabalho pedagógico. Campinas e Alínea. 2006.

MANTOAN, Maria Teresa Eglér. Inclusão escolar: o que é? Por quê? Como fazer? $2^{\mathrm{a}}$ edição. São Paulo: Editora Moderna, 2005.

MARTINEZ, Albertina Mitjáns, Criatividade no Trabalho Pedagógico e Criatividade na Aprendizagem: uma relação necessária? In TACCA, Maria Carmen V. Rosa. Aprendizagem e trabalho pedagógico. São Paulo: Editora Alínea, 2006.

DECLARAÇÃO DE SALAMANCA. Declaração Mundial sobre Necessidades Educativas Especiais: Acesso e qualidade. Trad. Edilson Alkmin da Cunha. 2. Ed. Brasília: CORDE, 1994.

SILVA, Queila. ROSA, Marcelo. A atuação dos professores de Educação Física com alunos deficientes. Revista Olhar Científico. Faculdades Associadas Ariquemes. V. 01, n.2, Ago./Dez. 2010.

MEC. Política de educação inclusiva. Disponível em: http://portal.mec.gov.br/index.php?option=com_content\&view=article\&id=12345:politica-deeducacao-inclusiva\&catid=302:politica-de-educacao-inclusiva\&Itemid=709. Acesso em: 29 de junho de 2017.

MANTOAN, Ma Teresa Eglér. Inclusão é o privilégio de conviver com as diferenças. In: Nova Escola, maio de 2005. MEC. Política de educação inclusiva. Disponível em: http://portal.mec.gov.br/index.php?option=com_content\&view=article\&id=12345:politica-deeducacao-inclusiva\&catid=302:politica-de-educacao-inclusiva\&Itemid=709. Acesso em: 29 de junho de 2017.

MITTLER, Peter. Educação inclusiva: contextos sociais. Trad. Windys Brazão Ferreira. Porto Alegre: Artemed, 2003.

SANTANA, Raquel Soares de. Ressignificação da prática pedagógica: aprendizagem do número numa perspectiva inclusiva. Dissertação de Mestrado. Universidade de Brasília. Brasília. 2010.

SASSAKI, Romeu Kazumi. Terminologia sobre deficiência na era da inclusão. Revista Nacional de Reabilitação, São Paulo, ano 5, nº. 24, jan./fev. 2002.

Inclusão: construindo uma sociedade para todos. $5^{\text {a }}$ edição. Rio de Janeiro: Editora WVA, 2004. TARDIF, Maurice. Saberes docentes e formação profissional, Petrópolis: Editora Vozes, 2002.

TUNES, Elizabeth; TACCA, Maria Carmen; BARTHOLO JUNIOR, Roberto dos Santos. O professor e o ato de ensinar. Caderno de Pesquisa, São Paulo: 2005.

VIGOTSKY, L. S. Fundamentos de Defectología. Obras Completas, Tomo V, Ed. Pueblo y Educación, Ciudad de la Habana, Cuba, 1995.

VIGOTSKY, L. S. A construção do pensamento e da linguagem. Trad: Paulo Bezerra. São Paulo: Editora Martins Fontes, 2001.

VIGOTSKY, L. S. A formação social da mente: o desenvolvimento dos processos psicológicos superiores. Trad: José Cipolla Neto, Luis Silveira Menna Barreto, Solange 